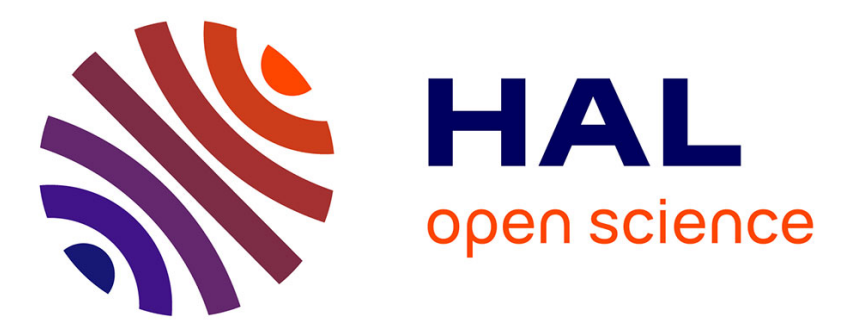

\title{
Influence of the annealing treatments on the luminescence properties of SiOSiO2 multilayers
}

\author{
O. Jambois, H. Rinnert, X. Devaux, M. Vergnat
}

\section{To cite this version:}

O. Jambois, H. Rinnert, X. Devaux, M. Vergnat. Influence of the annealing treatments on the luminescence properties of SiOSiO2 multilayers. Journal of Applied Physics, 2006, 100 (12), pp.123504. 10.1063/1.2402976 . hal-02164235

\section{HAL Id: hal-02164235 \\ https://hal.science/hal-02164235}

Submitted on 24 Jun 2019

HAL is a multi-disciplinary open access archive for the deposit and dissemination of scientific research documents, whether they are published or not. The documents may come from teaching and research institutions in France or abroad, or from public or private research centers.
L'archive ouverte pluridisciplinaire HAL, est destinée au dépôt et à la diffusion de documents scientifiques de niveau recherche, publiés ou non, émanant des établissements d'enseignement et de recherche français ou étrangers, des laboratoires publics ou privés. 


\title{
Influence of the annealing treatments on the luminescence properties of $\mathrm{SiO} / \mathrm{SiO}_{2}$ multilayers
}

\author{
O. Jambois, H. Rinnert, ${ }^{\text {a) }}$ X. Devaux, and M. Vergnat \\ Laboratoire de Physique des Matériaux (UMR CNRS No 7556), Nancy-Université, B.P. 239, \\ 54506 Vandouvre-lès-Nancy Cedex, France
}

(Received 25 July 2006; accepted 18 October 2006; published online 19 December 2006)

\begin{abstract}
The formation of silicon nanocrystals (Si-ncs) and their room temperature photoluminescence (PL) properties were investigated in samples elaborated by the evaporation method. Silicon oxide ( $\mathrm{SiO})$ single layer and $\mathrm{SiO} / \mathrm{SiO}_{2}$ multilayers with different $\mathrm{SiO}$ layer thicknesses from 1 to $5 \mathrm{~nm}$ were prepared and annealed at different temperatures up to $1050{ }^{\circ} \mathrm{C}$. The structure and the formation of Si-nc were studied by transmission electron microscopy (TEM) and by Fourier transform infrared (FTIR) absorption spectroscopy. It is demonstrated that the Si-ncs appear by the phase separation process from $\mathrm{SiO}$ due to the annealing treatments. Contrary to the $\mathrm{SiO}$ single layer, the multilayers are a powerful system to obtain highly luminescent $\mathrm{Si}$-nc and to control the Si-nc size for SiO layer thicknesses lower than or equal to $4 \mathrm{~nm}$. It is clearly shown that, in agreement with the quantum confinement theory, the PL energy is a decreasing function of the Si-nc size. However, thanks to the correlation between FTIR, TEM, and PL results, it is demonstrated that the PL energy is also strongly dependent on the quality of the matrix in which the Si-nc are embedded. A model based on the existence of a $\mathrm{SiO}_{x}$ shell surrounding the $\mathrm{Si}$-nc is proposed to explain the PL results. (C) 2006 American Institute of Physics. [DOI: 10.1063/1.2402976]
\end{abstract}

\section{INTRODUCTION}

Silicon nanocrystals have known very intensive research activity since last decade because of their very promising light emitting properties. The effect of the confinement of the exciton in the space leads to an enhancement of the radiative recombination rate and to an increase of the emission energy. Although bulk silicon is a very poor light emitter, Si-nc can emit light at room temperature. Considerable effort has then been consented in their elaboration, together with several techniques as ion implantation, ${ }^{1-3}$ direct evaporation of $\mathrm{SiO}$ (Ref. 4) or evaporation of Si under an oxygen atmosphere, ${ }^{5}$ plasma-enhanced chemical vapor deposition, ${ }^{6}$ and laser pyrolyses of silane in a gas flow reactor. ${ }^{7}$ In most of the experiments, the $\mathrm{Si}$-rich $\mathrm{SiO}_{2}$ system was chosen to promote the formation of $\mathrm{Si}$ aggregates. The formation of thin films is generally followed by a thermal annealing process to suppress defects to generate the Si aggregates and to crystallize them. The Si-nc formation process depends on the preparation technique used and plays a key role on the control of the $\mathrm{Si}$-nc size, on the size distribution, and on the quality of the confinement matrix.

$\mathrm{As} \mathrm{SiO}$ is thermodynamically less stable than the $\mathrm{Si}$ and $\mathrm{SiO}_{2}$ phases, thermal annealing treatment leads to the formation of the silicon particles, as shown in a previous study. ${ }^{4}$ While the size of the silicon particles cannot be controlled by this way, $\mathrm{SiO} / \mathrm{SiO}_{2}$ can be used to obtain size-controlled Si-nc, as shown by the work of Heitmann et al. ${ }^{8}$ In this study, we present photoluminescence properties of Si-nc embedded in a $\mathrm{SiO}_{2}$ matrix obtained by the evaporation technique, fully compatible with the microelectronics industry. Single $\mathrm{SiO}$ layer and $\mathrm{SiO} / \mathrm{SiO}_{2}$ multilayers are prepared. The influence

${ }^{a)}$ Electronic mail: rinnert@lpm.u-nancy.fr of the $\mathrm{SiO}$ layer thickness and of the annealing temperature $T_{a}$ are investigated by photoluminescence (PL) and Fourier transform infrared (FTIR) absorption spectroscopies and by transmission electron microscopy (TEM). A model based on the phase separation process is presented to explain the formation of Si-nc. It is shown that, contrary to the $\mathrm{SiO}$ single layers, the multilayers are efficient systems to obtain high quality luminescent Si-nc-based layers. The increase of the PL energy when the Si-nc size decreases is obtained, in qualitative good agreement with the prediction of the quantum confinement model. However, it is also demonstrated that the size of the $\mathrm{Si}$-nc is not the unique criterion that controls the PL energy. Indeed the correlation between PL properties and the structure of the films allowed us to show that $\mathrm{Si}$-nc with same sizes can emit at different energies if their $\mathrm{SiO}_{x}$ environment is different. This work leads us to propose a model where the Si-nc are surrounded by a suboxide $\mathrm{SiO}_{x}$ shell, involving in a lowering of the confinement effect.

\section{EXPERIMENTS}

The $\mathrm{SiO} / \mathrm{SiO}_{2}$ multilayers were prepared by successive thermal evaporation of a $\mathrm{SiO}$ powder and evaporation of fused silica glass performed by an electron beam gun. The deposition rate was controlled by a quartz microbalance system and was equal to $0.1 \mathrm{~nm} / \mathrm{s}$. The thickness of the $\mathrm{SiO}$ active layer was varied from 1 to $5 \mathrm{~nm}$, whereas, the $\mathrm{SiO}_{2}$ barrier thickness was maintained equal to $5 \mathrm{~nm}$. The silicon substrates were maintained at $100{ }^{\circ} \mathrm{C}$. For each sample, the total film thickness was around $200 \mathrm{~nm}$. Two single layers with a thickness equal to $200 \mathrm{~nm}$ were also prepared, one of 
$\mathrm{SiO}$, the other of $\mathrm{SiO}_{2}$. The samples were then annealed under vacuum with a pressure equal to $10^{-6}$ Torr at temperature in the range of $500-1050{ }^{\circ} \mathrm{C}$.

To follow the chemical composition of the silicon oxide matrix, the films were studied by Fourier transform infrared absorption measurements using a Perkin-Elmer 2000 spectrometer with a resolution of $4 \mathrm{~cm}^{-1}$. For each sample, a reference spectrum of an uncoated silicon substrate was subtracted from the experimental spectra. The average chemical composition of the $\mathrm{SiO}$ single layer was also analyzed by energy dispersive x-ray spectroscopy (EDXS).

Si-nc size distributions were measured from TEM images obtained with a $200 \mathrm{kV}$ Philips CM200 microscope. TEM analyses were carried out on cross section and on rearthinned samples, both prepared by mechanical thinning, using the tripod method (see Ref. 9), without ion milling. The size distribution of the Si-nc was obtained from rear-thinned samples, and to avoid the superposition of many Si-nc in the sample up-projected image, trilayer structures with one single $\mathrm{SiO}$ layer sandwiched between two $\mathrm{SiO}_{2}$ barrier layers were elaborated. It was verified that the luminescence properties of such samples were the same as for multilayers but with a lower intensity.

For room temperature photoluminescence measurements, optical emission was analyzed by a monochromator equipped with a 150 grooves/mm grating and by a chargedcoupled device detector cooled at $140 \mathrm{~K}$. The excitation was obtained by the 313 and $334 \mathrm{~nm} \mathrm{UV} \mathrm{lines} \mathrm{of} \mathrm{a} 200 \mathrm{~W}$ mercury arc lamp source. The response of the system was precisely calibrated with a tungsten calibration source.

\section{RESULTS AND DISCUSSION}

\section{A. Structure of the films}

FTIR absorption spectroscopy has been used in order to study the evolution of the matrix during the phase separation of the $\mathrm{SiO}$ layers in the multilayers. Indeed this method is a powerful way to measure the chemical composition of a silicon oxide layer. $\mathrm{Si}-\mathrm{O}-\mathrm{Si}$ groups give rise to several infrared absorption bands due to different vibrations. In particular, the asymmetric stretching vibration of the oxygen atom in the $\mathrm{Si}-\mathrm{O}-\mathrm{Si}$ group involves in a strong absorption located around $1000 \mathrm{~cm}^{-1}$. Moreover, because of the strong electronegativity of the oxygen atom, this absorption frequency is an increasing function of the oxygen content $x$ of the $\mathrm{SiO}_{x}$ layer. In the case of oxygen-doped amorphous silicon films and silicon dioxide films, these frequencies are equal to 940 and around $1075 \mathrm{~cm}^{-1}$, respectively. ${ }^{10,11}$ For the intermediate concentrations, a linear relation between $x$ and the frequency of the asymmetric stretching vibration is generally accepted in a homogeneous silicon oxide film. ${ }^{12,13}$

Figures 1(a)-1(c) show the FTIR absorption results concerning the $\mathrm{SiO}$ single layer, $\mathrm{SiO}_{2}$ single layer, and a multilayer with a $\mathrm{SiO}$ thickness equal to $4 \mathrm{~nm}$, respectively, for different annealing temperatures. All the samples show a band at around $1000 \mathrm{~cm}^{-1}$, characteristic of the asymmetric stretching mode of the $\mathrm{Si}-\mathrm{O}-\mathrm{Si}$ group. For the $\mathrm{SiO}$ single layer, the peak at $995 \mathrm{~cm}^{-1}$ of the as-deposited sample is a characteristic of the $\mathrm{SiO}$ composition whereas the sample

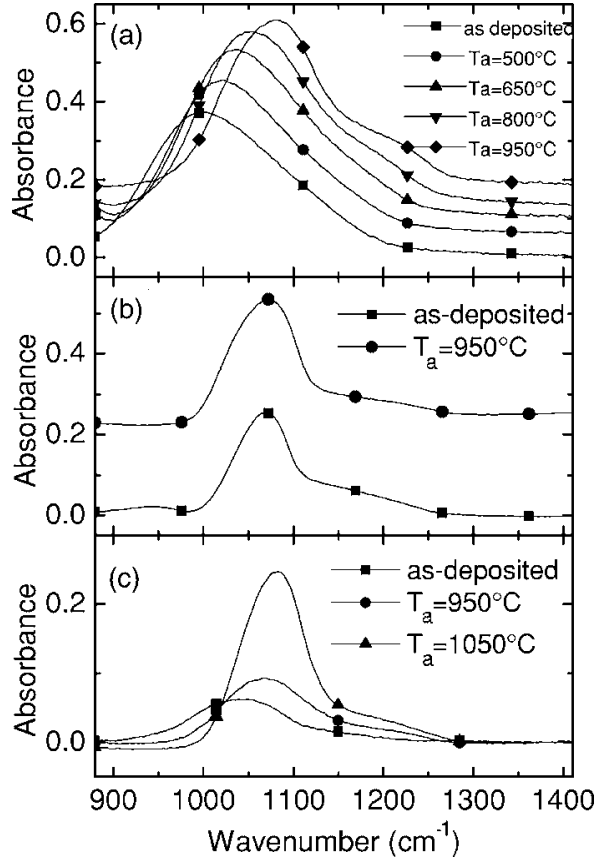

FIG. 1. Infrared absorption spectra from (a) a single $200 \mathrm{~nm} \mathrm{SiO}$ layer, (b) a single $200 \mathrm{~nm} \mathrm{SiO}$ layer, and (c) the active layer of the $\mathrm{SiO} / \mathrm{SiO}_{2}$ multilayers, for the as-deposited samples and for the samples annealed at the temperature $T_{a}$.

annealed at $950{ }^{\circ} \mathrm{C}$ shows a frequency absorption equal to $1075 \mathrm{~cm}^{-1}$, characteristic of $\mathrm{SiO}_{2}$. It must be noted that these absorption bands are large compared to that of a homogeneous stoichiometric $\mathrm{SiO}_{2}$ films which demonstrates that, in the sample annealed at $950{ }^{\circ} \mathrm{C}, \mathrm{SiO}_{2}$ domains exist in the layer but that $\mathrm{SiO}_{x}$ areas still exist too. The EDXS results show that the mean chemical composition of the samples remains constant and that no further oxidation appears neither at contact with ambient atmosphere nor by thermal annealing treatments. Thus the continuous evolution of the infrared absorption band towards the high wave numbers shows that a phase separation appears at around $500{ }^{\circ} \mathrm{C}$ and leads to the formation of pure silicon domains embedded in a $\mathrm{SiO}_{2}$ matrix. The same study was performed on the $\mathrm{SiO}_{2}$ single layer. The as-deposited layer shows an absorption located at $1072 \mathrm{~cm}^{-1}$ which does not move with the annealing treatments. It can be concluded that the chemical composition of the barrier layer is very close to $\mathrm{SiO}_{2}$ and that this layer is very stable. Only a weak peak at $940 \mathrm{~cm}^{-1}$, that can be attributed to some defects such as dangling bonds, disappears with annealing. The study of the multilayer is clearly more complicated because the absorption spectra take into account both the absorption of the active layers and the barrier layers. As the absorption of the $\mathrm{SiO}_{2}$ single layer for each annealing temperature and the whole thickness of $\mathrm{SiO}_{2}$ in the multilayers are known, a scrupulous subtraction of the $\mathrm{SiO}_{2}$ signal has been performed on the multilayers absorption spectra. As shown on Fig. 1(c), a shift toward higher wave numbers for increasing annealing temperature is observed, which suggests that the phase separation appears in the $\mathrm{SiO}$ layers of the multilayers. Moreover the spectroscopic signature of the $\mathrm{SiO}_{2}$ composition appears only at $1050{ }^{\circ} \mathrm{C}$ in the active layer, whereas this composition was obtained at 


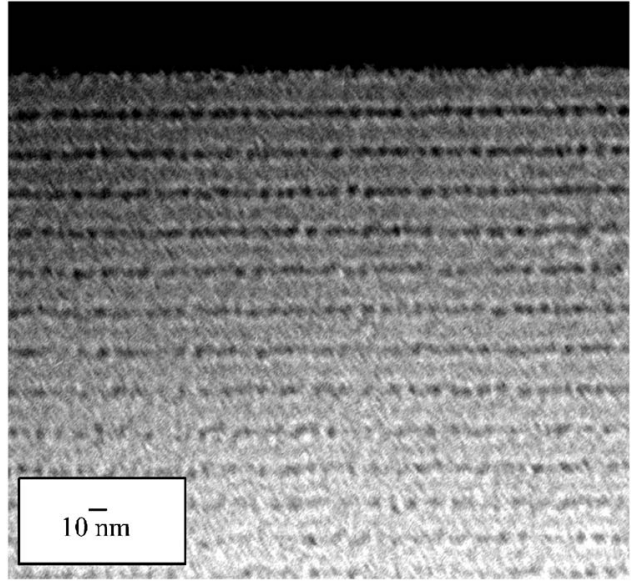

FIG. 2. Cross-section view of a multilayer with a $\mathrm{SiO}$ layer thickness equal to $3 \mathrm{~nm}$ and annealed at $1050{ }^{\circ} \mathrm{C}$.

$950{ }^{\circ} \mathrm{C}$ for the $\mathrm{SiO}$ single layer. This result is not surprising because the strain created by the stable $\mathrm{SiO}_{2}$ barrier layer probably prevents the phase separation from appearing at temperature as low as for the $\mathrm{SiO}$ single layer.

These FTIR results strongly suggest that some pure silicon domains should also exist in the multilayers after annealing. To obtain size-controlled Si-nc, it is important that the $\mathrm{SiO}_{2}$ layer remains stable and that the multilayer structure still exists at high annealing temperature. Typical TEM cross-section view micrograph of a multilayer with a $\mathrm{SiO}$ thickness equal to $3 \mathrm{~nm}$ and annealed at $1050{ }^{\circ} \mathrm{C}$ is represented in Fig. 2. The black lines are the active layers and the white bands are the $\mathrm{SiO}_{2}$ layers. This micrograph clearly shows that the multilayer structure remains stable after the thermal annealing treatments. Moreover, the $\mathrm{SiO}$ layers give rise to a discontinuous layer which contains the silicon nanoparticles. A plan view of the same sample clearly shows the $\mathrm{Si}$ nanoparticles and their crystalline character can be observed, both on the dark-field views and on the high resolution TEM images (see Ref. 14). To understand the growth mechanism of the Si-nc, structural study was performed for different annealing temperatures. For the $\mathrm{SiO}$ single layer, no crystalline character is detected on a layer annealed at $950{ }^{\circ} \mathrm{C}$. A great number of nanoparticles is seen at this temperature with a mean size below $2 \mathrm{~nm}$. For the sample annealed at $1000{ }^{\circ} \mathrm{C}$, the number of nanoparticles is lower than at $950{ }^{\circ} \mathrm{C}$ and the mean size is greater (see Ref. 15). As shown by the dark-field view, most of the nanoparticles are crystalline. The size distribution is very large with a nanocrystal size ranging from 5 to $10 \mathrm{~nm}$. For the multilayers, size distribution measurements were obtained from brightfield plan-view micrographs and are represented in Fig. 3 for the trilayer with a $\mathrm{SiO}$ thickness equal to $4 \mathrm{~nm}$ and for the annealing temperatures equal to 950,990 , and $1050{ }^{\circ} \mathrm{C}$. Each size distribution was fitted by a lognormal curve. As in the case of the $\mathrm{SiO}$ single layer, the trilayer annealed at $950{ }^{\circ} \mathrm{C}$ shows the presence of nanoparticles. The number of $\mathrm{Si}$ nanoparticles decreases with the annealing temperature, whereas the mean size is an increasing function of the temperature. The mean $\mathrm{Si}$-nc sizes are equal to 1.3, 2.2, and $4.1 \mathrm{~nm}$ for the annealing temperatures equal to 950, 990, and
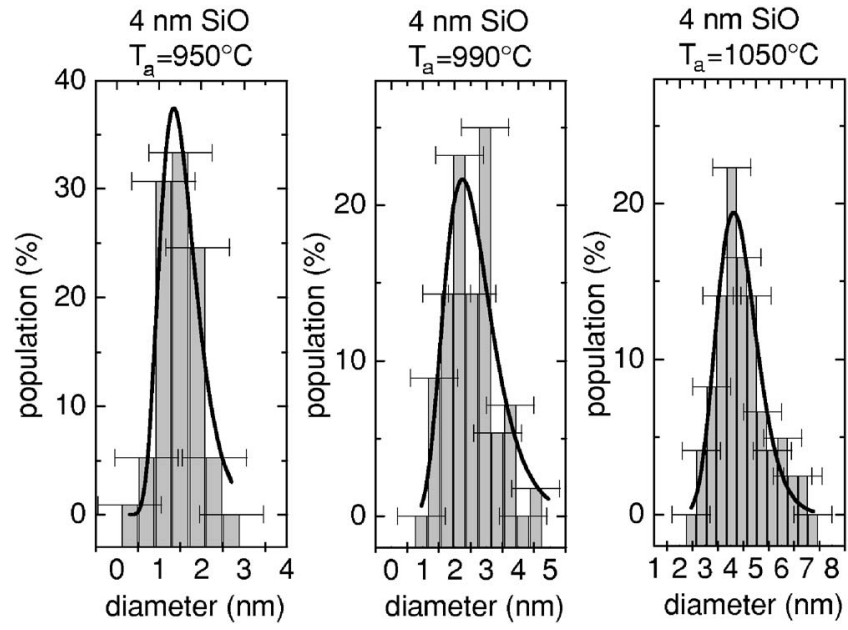

FIG. 3. Size distribution of the trilayer structures with a SiO layer thickness equal to $4 \mathrm{~nm}$ for annealing temperatures equal to 950,990 , and $1050{ }^{\circ} \mathrm{C}$.

$1050{ }^{\circ} \mathrm{C}$, respectively. Contrary to the $\mathrm{SiO}$ single layer, the size distribution is narrow. Moreover, the mean size is very close to the $\mathrm{SiO}$ layer thickness for the sample annealed at $1050{ }^{\circ} \mathrm{C}$.

Taking into account the FTIR absorption results and the TEM observations, it is possible to propose a growth mechanism for the Si-nc. From 500 to $800{ }^{\circ} \mathrm{C}$, the FTIR absorption spectrometry shows that a phase separation process appears but no particles are observed by TEM. We can conclude that this temperature range corresponds to a nucleation step, leading to a great number of nanoparticles. For an annealing temperature greater than $800{ }^{\circ} \mathrm{C}$, the growth phenomenon begins, probably allowed by the incomplete phase separation. Then some nanoparticles are visible with the TEM technique for samples annealed at $950{ }^{\circ} \mathrm{C}$. For higher temperatures, around $1000{ }^{\circ} \mathrm{C}$, a possible coalescence phenomenon could explain the growth of the nanocrystals until the limited size given by the $\mathrm{SiO}$ layer thickness. These results show that, contrary to the $\mathrm{SiO}$ single layer, it is possible to obtain size-controlled silicon nanocrystals embedded in a $\mathrm{SiO}_{2}$ matrix with the multilayer structure. Hence, several multilayers with different $\mathrm{SiO}$ layer thicknesses were prepared. The size distribution of the samples annealed at $1050{ }^{\circ} \mathrm{C}$ are represented in Fig. 4 for the $\mathrm{SiO}$ layer thicknesses equal to 2,3 , and $5 \mathrm{~nm}$. The mean sizes are equal to $1.8,3.2,4.1$, and $4.0 \mathrm{~nm}$ for the $\mathrm{SiO}$ layer thicknesses equal to $2,3,4$, and $5 \mathrm{~nm}$, respectively. These results show that the $\mathrm{Si}$-nc size is well controlled by the $\mathrm{SiO}$ layer thickness. The full widths at half maximum (FWHM) of the fitted curve are equal to $1.2,1.3,1.7$, and $4.6 \mathrm{~nm}$, which clearly shows that the size distribution remains narrow for $\mathrm{SiO}$ layer thickness lower than or equal to $4 \mathrm{~nm}$. For the $\mathrm{SiO}$ thickness equal to $5 \mathrm{~nm}$, the behavior tends to that of the $\mathrm{SiO}$ single layer and the size distribution becomes large.

\section{B. Photoluminescence properties}

The evolution of the PL properties is first presented as a function of the annealing temperature. No PL was obtained from the $\mathrm{SiO}_{2}$ single layer. Figure 5 shows the PL spectra of the $\mathrm{SiO}$ single layer and of the multilayer with a $\mathrm{SiO}$ thick- 

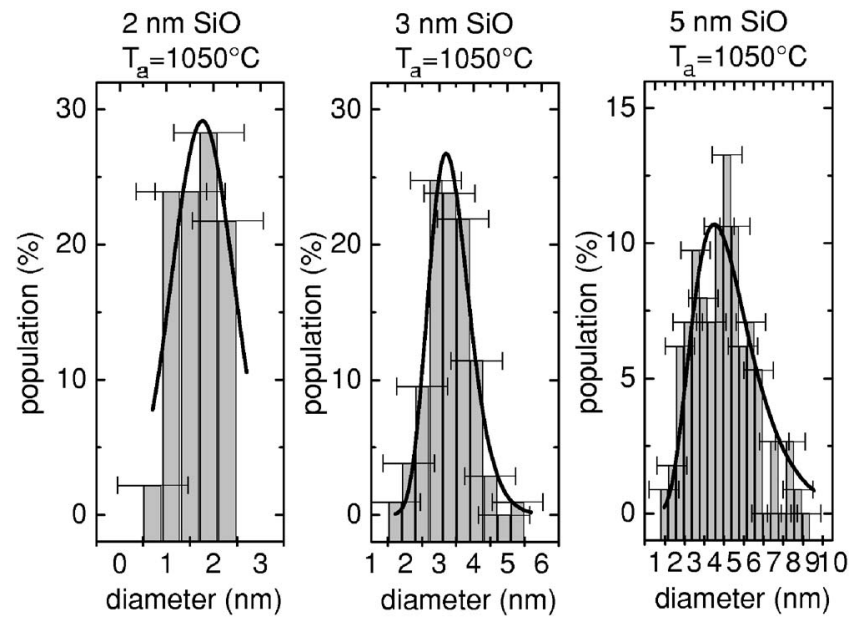

FIG. 4. Size distribution of the trilayers annealed at $1050{ }^{\circ} \mathrm{C}$ with $\mathrm{SiO}$ layer thicknesses equal to 2,3 , and $5 \mathrm{~nm}$.

ness equal to $3 \mathrm{~nm}$ for different annealing temperatures. The as-deposited $\mathrm{SiO}$ single layer shows a large band at $550 \mathrm{~nm}$, which is generally attributed to defect states of $\mathrm{SiO}_{x}$. When the sample is annealed, the intensity of this band decreases and a new band appears at higher wavelengths. For the samples annealed at $950{ }^{\circ} \mathrm{C}$, this new PL band is very broad, with a weak intensity and located at around $750 \mathrm{~nm}$. For higher annealing temperature, no PL is observed anymore. This PL band could be due to the presence of silicon nanoparticles and/or to interface states between the silicon particles and the silicon oxide matrix. The weak PL intensity could be explained by the presence of nonradiative defects or by a poor confinement quality of the matrix due to the probable presence of a substoichiometric $\mathrm{SiO}_{x}$ area around the silicon nanoparticles. An annealing at higher temperature should improve the PL intensity. Unfortunately, for annealing temperatures higher than $950{ }^{\circ} \mathrm{C}$, the silicon nanoparticles become too large to present a confinement effect. The exact origin of the PL band is still unclear, but the conclusion is that the single layer with the stoichiometry $\mathrm{SiO}$ is not an

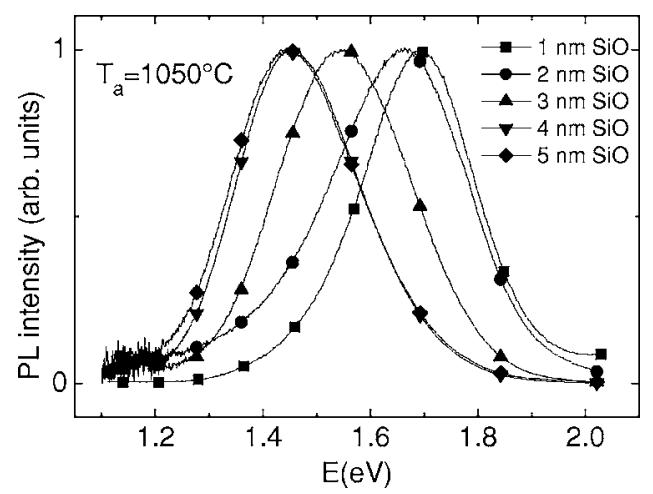

FIG. 6. Normalized PL spectra of multilayers annealed at $1050{ }^{\circ} \mathrm{C}$ for different $\mathrm{SiO}$ layer thicknesses.

interesting system to obtain highly luminescent Si-nc, contrary to some $\mathrm{Si}$-rich $\mathrm{SiO}_{2}$ layers with a lower $\mathrm{Si}$ concentration than in $\mathrm{SiO}$, which can give high PL yields.

For the multilayer annealed at temperatures lower than or equal to $950{ }^{\circ} \mathrm{C}$, the PL behavior is similar to that of the $\mathrm{SiO}$ single layer. Interestingly, for higher annealing temperatures, the PL is much more intense, with a lower FWHM than the $\mathrm{SiO}$ single layer PL band, and located at around $800 \mathrm{~nm}$. This new sharp PL band is correlated to the existence of Si-nc, as shown by the TEM characterization. The multilayer structure is then efficient for two reasons. First, the $\mathrm{SiO}_{2}$ barrier layers limit the growth of the nanoparticles below the critical size for confinement. Second, the Si-nc are embedded in $\mathrm{SiO}_{2}$ matrix allowing a well passivated interface and a sufficiently high energy barrier to confine the exciton in the Si-nc.

In the next, the correlation between the PL energy and the size distribution is discussed. The normalized PL spectra of the multilayers annealed at $1050{ }^{\circ} \mathrm{C}$ are presented in Fig. 6 for the different $\mathrm{SiO}$ layer thicknesses. They are very similar for the $\mathrm{SiO}$ layer thicknesses equal to 4 and $5 \mathrm{~nm}$ and when the size is reduced from 4 to $1 \mathrm{~nm}$, a blueshift is clearly obtained. The evolution of the energy of the PL peak

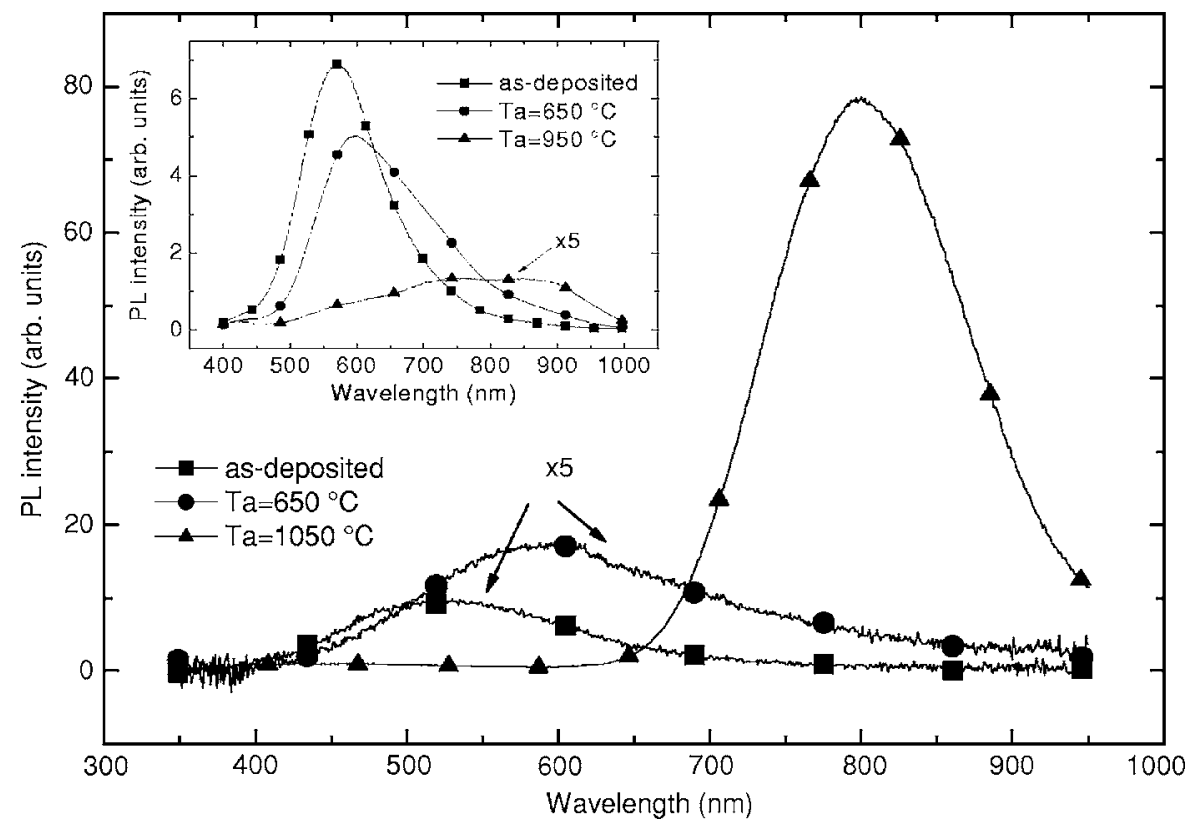

FIG. 5. Photoluminescence spectra of a multilayer with a $3 \mathrm{~nm} \mathrm{SiO}$ layer thickness annealed at different temperatures. The inset represents the PL spectra for the single $\mathrm{SiO}$ layer. 


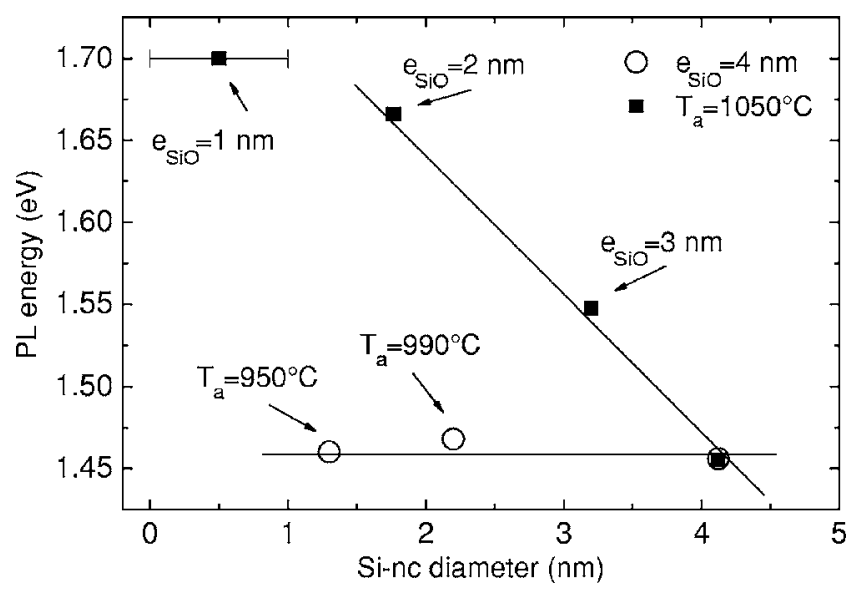

FIG. 7. PL energy of the multilayers as a function of the nc-Si diameter for $T_{a}$ equal to $1050{ }^{\circ} \mathrm{C}$ (full squares). The empty circles represent the PL energy of the multilayer with a $\mathrm{SiO}$ thickness equal to $4 \mathrm{~nm}$, for different annealing temperatures. The lines are guides for the eyes.

maximum is represented by full squares in Fig. 7 as a function of the Si-nc mean size. Let us note that for the sample with $1 \mathrm{~nm}$, whereas the PL is well measured, it has been impossible to detect $\mathrm{Si}$-nc with the TEM technique, certainly because their size is under the spatial resolution of the TEM. Thus, the diameter has been estimated to less than $1 \mathrm{~nm}$. The PL energy is a decreasing function of the Si-nc size, which is in qualitative good agreement with the quantum confinement model, as already observed experimentally and theoretically by many authors. ${ }^{2,6,8}$ The PL energy of the samples with a $1 \mathrm{~nm} \mathrm{SiO}$ layer, equal to $1.7 \mathrm{eV}$, is very small compared to the quantum confinement theory prediction that gives an energy value higher than $4 \mathrm{eV} .{ }^{16,17} \mathrm{~A}$ very important quantitative disagreement with theory has already been obtained in literature for the Si-nc sizes lower than $2 \mathrm{~nm}$. Several explanations have been proposed to understand this result, one based on the existence of electronic states located in the gap of the Si-nc (Refs. 18 and 19) and another on the existence of strong strains on Si-nc with a size lower than $2 \mathrm{~nm}$ induced by the $\mathrm{SiO}_{2}$ matrix. ${ }^{20}$ The energy-size correlation was also studied for samples with the same $\mathrm{SiO}$ layer thickness but with different annealing temperatures. The PL energy of these samples is represented by empty circles on Fig. 7, for multilayers with a $\mathrm{SiO}$ layer thickness equal to $4 \mathrm{~nm}$. This evolution shows an atypical behavior of the PL energy evolution with the Si-nc size. Indeed, the PL energy is nearly independent on the annealing temperature, whereas the size of the Si-nc increases. Furthermore, the comparison of the data represented in Fig. 7 shows that for a given size of Si-nc, different PL energies can be obtained. A low PL energy in a sample annealed at $950{ }^{\circ} \mathrm{C}$ could be explained by the absence of PL from the smaller clusters of the size distribution, which could be due to a size dependence of the quantum yield or to a poor passivation of the small clusters, compared to the larger ones. But such hypotheses would imply a large size distribution, in which clusters as large as $4 \mathrm{~nm}$ should be present. On the contrary, the structural study shows that the sample annealed at $950{ }^{\circ} \mathrm{C}$ presents a narrow size distribution. Moreover, in this sample no cluster with a size equal to around $4 \mathrm{~nm}$ is observed that could explained the low PL energy at $1.45 \mathrm{eV}$.

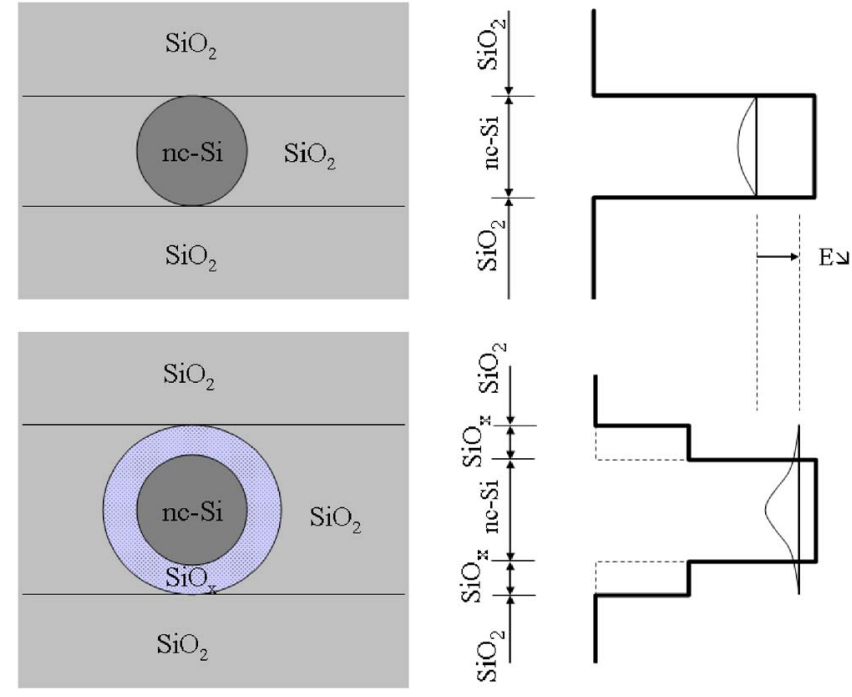

FIG. 8. (Color online) Qualitative modeling of the Si-nc environment with a substoichiometric shell, and its consequences on the exciton confinement potential.

Consequently, to understand this peculiar result, the influence of the $\mathrm{SiO}_{x}$ matrix on the PL energy must be considered. The results show that two Si-nc of the same diameter exhibit different PL energies. For example, a Si-nc of around $2 \mathrm{~nm}$ diameter in a sample annealed at $1050{ }^{\circ} \mathrm{C}$ exhibits a PL peak maximum at $1.65 \mathrm{eV}$, whereas a $\mathrm{Si}-\mathrm{nc}$ of same diameter in a sample annealed at $990{ }^{\circ} \mathrm{C}$ shows a PL peak maximum at $1.46 \mathrm{eV}$. In the same time, FTIR measurements have shown that the matrix becomes very close to $\mathrm{SiO}_{2}$ only after an annealing at $1050{ }^{\circ} \mathrm{C}$. Thus, the matrix of the sample annealed at $990{ }^{\circ} \mathrm{C}$ is still a Si-rich $\mathrm{SiO}_{2}$ compound. Thus, the confinement energy is probably lower for this sample than for the sample annealed at $1050{ }^{\circ} \mathrm{C}$. This matrix confinement energy difference could be at the origin of different PL energies for identical Si-nc size. The existence of a substoichiometric shell around the Si-nc was suggested by Kovalev et $\mathrm{al}^{21}$ and Daldosso et al. ${ }^{22}$ and its influence on PL energy was proposed. This hypothesis can be represented by a model involving a Si-rich $\mathrm{SiO}_{2}$ shell around the $\mathrm{Si}$-nc, as schematically represented in Fig. 8. If we consider first a Si-nc in a sample annealed at $1050{ }^{\circ} \mathrm{C}$, at this temperature, the $\mathrm{Si}-\mathrm{nc}$ has reached its limit size, and moreover, the phase separation is finished, implying that the $\mathrm{Si}-\mathrm{nc}$ is completely embedded in a $\mathrm{SiO}_{2}$ matrix. The conduction band in the transverse direction is schematized at the right. The wave function of the electronic state penetrates the $\mathrm{SiO}_{2}$ matrix due to a finite potential barrier. For the lower annealing temperatures, for example, $990{ }^{\circ} \mathrm{C}$, the phase separation is not finished. So, on the one hand, the Si-nc have not reached their limit size given by the $\mathrm{SiO}$ layer thickness. On the other hand, the matrix around the $\mathrm{Si}-\mathrm{nc}$ is still a Si-rich $\mathrm{SiO}_{2}$ shell. In this case, the confinement energy is lower and the wave function spreads more in the oxide. The presence of this shell, not visible by TEM, could explain why the Si-nc size is not the unique parameter driving the PL energy. The quality of the confinement matrix probably plays a crucial role on the PL energy. In this scheme the nontrivial evolution presented in Fig. 7 is explained. At annealing temperature 
around $950{ }^{\circ} \mathrm{C}$, the Si-nc are small, but the exciton created inside is more delocalized because of the poor confinement quality of the silicon oxide around. The energy confinement is therefore small. At higher temperature, the $\mathrm{Si}$-nc are bigger, but the created excitons are better confined, implying a higher confinement energy. Moreover this result could probably explain the different size dependences of the PL energy of the Si-nc observed in the literature and, in particular, why the quantitative agreement with theory is not perfect.

\section{CONCLUSION}

Structure and photoluminescence properties of single $\mathrm{SiO}$ layer and $\mathrm{SiO} / \mathrm{SiO}_{2}$ multilayers were studied as a function of the annealing treatments. It was demonstrated that if the $\mathrm{SiO}$ single layer do not allow us to obtain well-passivated luminescent $\mathrm{Si}-\mathrm{nc}, \mathrm{SiO} / \mathrm{SiO}_{2}$ multilayers are good systems to prepare size-controlled Si-nc-based layers with a high luminescence efficiency. The mean size of the Si-nc is given by the $\mathrm{SiO}$ layer thickness, in which the phase separation process into $\mathrm{Si}$ and $\mathrm{SiO}_{2}$ appears. The size can be controlled for $\mathrm{SiO}$ layer thickness lower than or equal to $4 \mathrm{~nm}$ and the FWHM of the size dispersion is lower than $2 \mathrm{~nm}$. As predicted by the quantum confinement model, the PL energy is a decreasing function of the Si-nc size. Moreover, the correlation of the optical properties of the multilayers with the microstructure study leads to a model where the Si-nc are surrounded by a $\mathrm{SiO}_{x}$ shell if the phase separation process is not complete. This shell involves in a lowering of the confinement energy of the exciton compared to the case of a $\mathrm{SiO}_{2}$ matrix. That means that the Si-nc size clearly plays an important role in the PL energy, but the confinement matrix quality is also strongly implicated in the energy of the PL.
${ }^{1}$ J. Linnros, N. Lalic, A. Galeckas, and V. Grivickas, J. Appl. Phys. 86, 6128 (1999).

${ }^{2}$ B. Garrido Fernandez, M. Lopez, C. Garcia, A. Perez-Rodriguez, J. R. Morante, C. Bonafos, M. Carrada, and A. Claverie, J. Appl. Phys. 91, 798 (2002)

${ }^{3}$ T. Shimizu-Iwayama, N. Kurumado, D. E. Hole, and P. D. Townsend, J. Appl. Phys. 83, 6018 (1998).

${ }^{4}$ H. Rinnert, M. Vergnat, G. Marchal, and A. Burneau, Appl. Phys. Lett. 72, 3157 (1998).

${ }^{5}$ M. Molinari, H. Rinnert, and M. Vergnat, Appl. Phys. Lett. 82, 3877 (2003).

${ }^{6}$ F. Iacona, G. Franzo, and C. Spinella, J. Appl. Phys. 87, 1295 (2000).

${ }^{7}$ G. Ledoux, O. Guillois, D. Porterat, C. Reynaud, F. Huisken, B. Kohn, and V. Paillard, Phys. Rev. B 62, 15942 (2000).

${ }^{8}$ J. Heitmann, F. Muller, L. Yi, M. Zacharias, D. Kovalev, and F. Eichhorn, Phys. Rev. B 69, 195309 (2004).

${ }^{9}$ J. Benedict, R. Anderson, and S. J. Klepeis, Mater. Res. Soc. Symp. Proc. 254, 121 (1992).

${ }^{10}$ G. Lucovsky, J. Yang, S. S. Chao, J. E. Tyler, and W. Czubatyj, Phys. Rev. B 28, 3225 (1983).

${ }^{11}$ S. Y. Lin, J. Appl. Phys. 82, 5976 (1997).

${ }^{12}$ P. G. Pai, S. S. Chao, Y. Takagi, and G. Lucovsky, J. Vac. Sci. Technol. B 4, 689 (1986).

${ }^{13}$ H. Rinnert, M. Vergnat, and A. Burneau, J. Appl. Phys. 89, 237 (2001).

${ }^{14}$ O. Jambois, H. Rinnert, X. Devaux, and M. Vergnat, J. Appl. Phys. 98, 046105 (2005).

${ }^{15}$ G. Wora-Adeola, O. Jambois, P. Miska, H. Rinnert, and M. Vergnat, Appl. Phys. Lett. 89, 101920 (2006).

${ }^{16}$ K. Nishio, J. Koga, T. Yamaguchi, and F. Yonezawa, Phys. Rev. B 67, 195304 (2003).

${ }^{17}$ J. P. Proot, C. Delerue, and G. Allan, Appl. Phys. Lett. 61, 1948 (1993).

${ }^{18}$ M. V. Wolkin, J. Jorne, P. M. Fauchet, G. Allan, and C. Delerue, Phys. Rev. Lett. 82, 197 (1999).

${ }^{19}$ I. Vasiliev, J. R. Chelikowsky, and R. M. Martin, Phys. Rev. B 65, 121302 (2002).

${ }^{20}$ G. Hadjisavvas and P. C. Kelires, Phys. Rev. Lett. 93, 226104 (2004).

${ }^{21}$ D. Kovalev, H. Heckler, M. Ben-Chorin, G. Polisski, M. Schwartzkopff, and F. Koch, Phys. Rev. Lett. 81, 2803 (1998).

${ }^{22}$ N. Daldosso et al., Phys. Rev. B 68, 085327 (2003). 